\title{
Transforming Our Practice and Making Every Bite Count
}

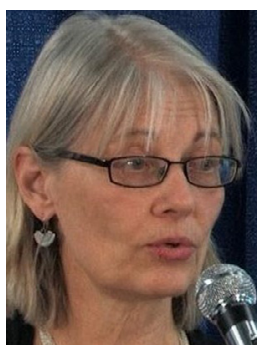

On June 5, 2021, the global family celebrated World Environment Day with the theme "Ecosystem Restoration" and called for not only conservation but also recovering systems that have been degraded or destroyed.

This World Environment Day also officially launched the United $\mathrm{Na}$ tions Decade of Ecosystem Restoration, a decade addressing various ecosystem challenges around the world. Everyone around the world resides in 1 of the 8 identified ecosystems, including fresh waters, urban areas, forests, and farmland. ${ }^{2}$ In other words, wherever you live is your ecosystem and the opportunity to be part of the \#RestorationGeneration.

We have now spent 2 decades of effort to make progress toward the agreed upon global biodiversity goal of "Living with Nature" by 2050. The 2020 Global Biodiversity Outlook 5 by the UN Convention on Biological Diversity is the latest report on a decade of effort to meet biodiversity targets, and, disappointingly, none of the goals were met and various pressures are, in fact, worsening the state of nature. ${ }^{3}$ Clearly, we are at a serious crossroads with substantial changes needed to the way we live on the planet, including transforming our food system.

Members have many opportunities to engage in system thinking and begin to move into action that supports rather than degrades nature. The 2019 SNEB position paper focused on the Importance of Including Environmental Sustainability in Dietary Guidance ${ }^{4}$ and provided a summary of the current environmental concerns, including the ecosystem changes that are leading to land and water degradation and serious biodiversity loss and considerations of diet changes. Our 2021 annual conference, August 8-10, 2021, followed by the New Orleans "deep dive" meeting August 26-27, 2021, provide many opportunities to consider the system changes necessary to meet sustainability goals within more equitable societies.

For many of us, this time of year provides a celebration of seasonal abundance and increased local varieties. Noticing your local and regional biodiversity, exploring the unique varieties within your ecosystem, and connecting directly with farmers are immediate actions we can take. The focus on diet diversity within food groups that incorporates more local foods purchased directly from the farmer helps make every bite count in ways that benefit the environment, celebrates our cultural and agricultural heritage, multiplies local investment, and provides nutrientrich foods.

Supporting household, school, and community gardens that focus on increasing biodiversity; introducing hunting, foraging, and fishing to youth; and incorporating regional foods in our institutions are other actions that support domesticated and wild biodiversity and increase awareness of our regional ecosystems.

Food and nutrition education is quickly evolving as we consider the challenges of significant change within this decade and a renewed focus on ecosystem vitality. Let's make every bite count in as many ways as possible.

Jasia (Jayne) Steinmetz, RD, CD President, Society for Nutrition Education and Behavior

\section{REFERENCES}

1. Geneva Environment Network. World Environment Day. https://www.genevaenvironmentnetwork.org/world-environment-day/\#scroll-nav_2. Accessed June 13, 2021.

2. United Nations Decade on Ecosystem Restoration. Types of ecosystem restoration. https://www.decadeonrestoration. org/types-ecosystem-restoration. Accessed June 4, 2021.

3. Secretariat of the Convention on Biological Diversity. Global Biodiversity Outlook 5 - Summary for Policy Makers. Secretariat of the Convention on Biological Diversity; 2020.

4. Rose D, Heller MC, Roberto CA. Position of the Society for Nutrition Education and Behavior: the importance of including environmental sustainability in dietary guidance. J Nutr Educ Behav. 2019;51:3-15. e1. 